\title{
EL DISPOSITIVO GUBERNAMENTAL, SU TOTALIZACIÓN MODERNA Y EL AFUERA DE LOS PAGANOS
}

\author{
The Governmental Dispositive, its Modern Totalization \\ and the Outside of the Pagans
}

Gonzalo Díaz Letelier ${ }^{1}$

Universidad de Chile

gonz.diaz.letelier@gmail.com

\section{Resumen}

A partir de la distinción que Michel Foucault hace, en el seno de su concepto de subjetivación, entre la "sujeción" y el "arte de vivir", enfocaremos en un primer momento la descripción genealógicoarqueológica de la deriva de las tecnologías de sujeción -producción de subjetividad-que van desde el poder pastoral de corte eclesiástico hasta el poder gubernamental de corte estatal y el poder mercantil-veridictivo de corte post-estatal. Sobre esta base consideraremos la deriva totalitaria moderna, que en Foucault tiene el carácter de una biopolítica, como convergencia y anudamiento del "doble vínculo" entre procedimientos de totalización política y técnicas de individualización moral -en este sentido haremos referencia, por una parte, a las indicaciones de Giorgio Agamben respecto de la confluencia totalitaria entre soberanía política y gubernamentalidad económica, y por otra parte, al vínculo que plantea Rodrigo Karmy entre el dispositivo gubernamental moderno y el concepto biopolítico de "civilización". Para finalizar, intentaremos pensar, en conexión con la idea de un arte de vivir en Foucault y bajo nuestra noción propuesta de paganismo, la experiencia del "afuera" como revocación de la gloria del reino: la posibilidad de una cierta vida ateológica y anárquica que ponga en cuestión la ontoteología de la metafísica que articula el

\footnotetext{
1 Académico del Departamento de Filosofía de la Universidad de Santiago; miembro integrante del Colectivo de Estudios Críticos sobre Biopolítica y Orientalismo del Centro de Estudios Árabes de la Universidad de Chile.
} 
proyecto civilizatorio occidental; vida ateológica y anárquica que, como tal, reivindique la potencia de otra relación entre vida y forma, una relación que implique una circulación sin acumulación soberano-equivalencial de la vida y sus producciones -contra las formas occidentales hegemónicas de circulación con patrón de acumulación en las esferas política, económica, estética, semántica y moral.

Palabras clave: poder, subjetivación, soberanía, gubernamentalidad, totalitarismo, biopolítica, civilización.

\section{Abstract}

From Michel Foucault's distinction within his concept of subjectivation, between the "subjection" and the "art of living", we will focus initially on the genealogical-archaeological description of the drift of technologies of subjection -production of subjectivity- that go from the ecclesiastical pastoral power to governmental power of state and post-state merchantveridictive power. On this basis, we will consider the modern totalitarian drift, wich in Foucault has the character of a biopolitics, as convergence and knotting of the "double bind" between procedures of political totalization and techniques of moral individualization -in this sense we will refer, on the one hand, to Giorgio Agamben's indications about the totalitarian confluence between political sovereignty and economic governmentality, and on the other hand, to the link proposed by Rodrigo Karmy between the modern governmental dispositive and the modern biopolitical concept of "civilization". Finally, we will try to think, in connection with the idea of an art of living in Foucault and under our proposed concept of paganism, the experience of the "outside" as revocation of the glory of reign: the possibility of a certain atheological and anarchic life that would put in question the ontotheology of metaphysics that articulates the Western civilizational project; atheological and anarchic life wich, as such, claims the potentiality of another relationship between life and form, a relationship involving a circulation without sovereignequivalential accumulation of life and their productions -against Western hegemonic forms of circulation with pattern of accumulation in the political, economic, aesthetic, semantical and moral spheres.

Keywords: power, subjectivation, sovereignty, governmentality, totalitarism, biopolitics, civilization. 
Uno de los conceptos claves del pensamiento de Michel Foucault es el de subjetivación (subjectivation), acuñado en correspondencia con un método histórico-filosófico cuyos procedimientos básicos son la arqueología y la genealogía, en el horizonte de una triada de indicadores formales constituida por las coordenadas del poder, el saber y la moral -unos indicadores que apuntan en cada caso al horizonte material del juego histórico de mutua efectualidad entre las instituciones y los discursos, y de las formas de vida que de tal juego resultan ${ }^{2}$. Se trata de una genealogía de la formasujeto al hilo de una arqueología del juego saber-poder en Occidente, correspondiendo la forma-sujeto a la forma de vida que en cada caso constituye una determinada moral.

En Nietzsche la genealogía consistía en la exposición de la génesis -es decir, del nacimiento en el tiempo o gestación histórica- de las cosas humanas a través de la dinámica de las relaciones de poder y significación: la genealogía se hace acerca de cosas que tendemos a percibir ahistóricamente, naturalizadas, eternas. Mostrar el nacimiento de las cosas es mostrar que no siempre fueron así, que fueron de otro modo y que pueden ser de otro modo. En la deriva nietzscheana de Foucault, la genealogía opera como un método histórico de exposición de las formaciones de los sujetos y de las cosas en el plexo de las relaciones dinámicas de poder $y$ significación a través de la historia, en virtud de una puesta en

\footnotetext{
${ }^{2}$ Cfr. M. Foucault, "Nietzsche, la genealogía y la historia", en: Microfísica del poder, Editorial La Piqueta, Madrid, ${ }^{3} 1992$; y M. Foucault, "Crítica y Aufklärung", Revista de Filosofía ULA, No. 8 (1995), pp. 33-45.
} 
juego esencialmente estratégica de los discursos y las instituciones: constitución de sujetos en el plano moral y constitución de objetos en el plano del saber -objetos entre los cuales se cuenta la propia forma-sujeto de acuerdo a una sanción normalizadora, a la sanción objetivante de un "alma" que en cada caso constituye "la prisión del cuerpo" (Michel Foucault, 2004: 36). La arqueología, método ensamblado a la genealogía, consiste precisamente en la exposición del nexo saber-poder que sostiene en su vigencia, allí donde es aceptada como vigente, una forma de vida y su gramática de las relaciones sociales, con sus discursos, instituciones y subjetividades correspondientes. Es decir, se trata de hacer visibles las estructuras sociales discursivo-institucionales que capturan a los vivientes encarnándose en ellos: los vivientes le dan así vida psíquica a las estructuras sociales del poder y de la verdad en su mutua efectualidad -esto es lo que se llama aquí un "proceso de subjetivación" en función de los dispositivos.

En suma, tenemos en la genealogía el aspecto diacrónico del método, propiamente histórico, y junto con ello tenemos en la arqueología el aspecto sincrónico del método, como visibilización del juego entre lo discursivo y lo extradiscursivo que, en su articulación, constituyen en cada caso los dispositivos subjetivantes en vigor.

El rendimiento de esto es una restitución arqueológicogenealógica de la escena material de la historia, de esa escena cuya materialidad se halla reprimida por las prácticas enunciativas que se mantienen en planos como los del discurso soberanista de la moderna filosofía contractualista 
del derecho o la historiografía de los vencedores ${ }^{3}$. Tal restitución implica a su vez la impugnación de la referencia metafísica a un sujeto trascendental -tal como ocurría esta referencia, por ejemplo, en los discursos filosóficos de Descartes, Kant o, en cierto modo, en la fenomenología. En este sentido se trata de una impugnación del recurso metafísico a la sedimentación antropológica occidental de un hombre-sujeto abstraído del campo de los acontecimientos históricos y sociales, esto es: el recurso teórico a una subjetividad comprendida como substancia o cosa, como algo dado a priori en su plenitud cósica y "natural", antes de su puesta en juego en el mundo y reprimiendo la visibilidad de tal puesta en juego como condición de la propia existencia en la definición de su norma antropológica. Esta restitución de la escena material de la historia y la impugnación de la ficciónsujeto trascendental conlleva en Foucault un vuelco en la interpretación de los conceptos de subjetividad y poder, al hilo de una puesta entre paréntesis del "privilegio teórico" que la filosofía política había conferido desde hace siglos al modelo de análisis soberano-jurídico por sobre el análisis de los fenómenos relativos a la producción de subjetividad inherentes a la lógica gubernamental. Pues lo que ha sido descuidado por la filosofía política "clásica" ha sido precisamente el conjunto de las tecnologías de producción de subjetividad, en favor de un enfoque del poder soberano y su articulación jurídica del "cuerpo social" en el horizonte de un discurso mítico, con su reverso represivo y mortífero cuando

${ }^{3}$ Respecto de la práctica discursiva "soberanista", ver M. Foucault, Defender la sociedad (Curso en el Collège de France, 1975-1976), Editorial F.C.E., México, ${ }^{1} 2000$, p. 67 y ss. 
se trata de su operación efectiva. Si la lógica del poder soberano se expresa en la fórmula "hacer morir o dejar vivir", la del poder gubernamental se declara en esta otra: "hacer vivir y dejar morir". Hacer vivir en un determinado sentido, es decir: definir y promover una forma de vida respecto de la cual toda alteridad es o vida residual o vida que se escapa. En todo caso vida "abandonada". Se trata de pensar el doble vínculo de la vida con el poder en Occidente, atendiendo a su moderna articulación en un ensamble biopolítico que implica, por una parte, la relación soberanía/obediencia en función de un "poder centralizado" en el sujeto soberano y de los estados de dominación que éste pone en obra en virtud de una territorialización jurídica, $y$, por otra parte $-y$ esto es lo que le interesa enfocar a Foucault-, la relación gubernamentalidad/sujeción en función de un poder descentrado y circulante, diseminado a ras del cuerpo social a través de prácticas cotidianas y espacios formativos de asimetría institucionales (Michel Foucault, 200: 112ss). En este horizonte ya no se cuenta en el ejercicio teorético con un sujeto substancial, ya sea soberano $u$ oprimido heterónomamente, sino que lo que aparece ante el lente micrométrico de la teoría es el proceso de subjetivación, evento performático que tiene el carácter de un quiasma, de una efectualidad resultante en el seno de un plexo de relaciones de poder y significación en las que se halla la vida envuelta en cada caso.

Ahora bien, la trayectoria de los focos en la investigación de Foucault muestra un desplazamiento teórico que va desde el estudio de las epistemes, y más tarde de los dispositivos, 
hacia la cuestión de las prácticas de sí mismo, lo que conlleva un tránsito desde las formas de constitución de la subjetividad por sujeción hacia aquellas en que se pone en juego la libertad de una estética de la existencia o arte de vivir. Foucault opera, pues, en el seno de su concepto de subjetivación, una distinción entre aquella subjetividad que resulta de la vida capturada por la variedad de tecnologías puestas en juego en los dispositivos soberanogubernamentales $y$ aquella que es fruto inventivo $y$ aventurado de una estética de la existencia, esto es, de una existencia que se escapa en virtud de la potencia de una imaginación desprendida y disidente, que se resiste a ser organizada o funcionalizada por el dispositivo por el que se halla condicionada en principio -en principio en el sentido de un a priori fáctico, histórico y contingente. Instituyente, la vida se da sus formas -y así "termina" poniendo en la clausura de una obra su potencia-; pero también puede escapar de ellas y así desobra y libera su potencia, radicalmente impropia, es decir: asubjetiva, lúdica y común, destituyente.

No obstante, si consideramos específicamente el fenómeno de la sujeción (assujettissement), la potencia de una imaginación organizada y funcionalizada por el dispositivo es la que se define, en cada caso, por la captura del viviente en una interioridad subjetiva que lo somete, pero que lo somete sólo en la medida en que él se acoge a ella y deviene así sujeto. Hay, pues, sujeción por reproducción -o familiar $o$ estratégica- de la facticidad en que habitamos, y junto con ello la hay también por acción formativa en los espacios asimétricos de las instituciones disciplinarias que condicionan 
la trayectoria de nuestro deseo y las habitualidades que definen la orientación efectiva del cuerpo y sus usos, de su imaginación y sus comportamientos declarativos. Además, hay efectos de sujeción al ser vencidos en la lucha políticoeconómica y sobrevivir en un estado de dominación, es decir, en el seno de un dispositivo cuya apertura y cerradura de posibilidades vitales no hemos elegido y que llega a determinar fácticamente, sin embargo, nuestra potencia actual (Judith Butler, 2001: 12) -la relación de poder implica una dinámica de apertura multilateral de posibilidades, ya sea en juego o en conflicto, y, cuando esta dinámica se resuelve en un determinado sentido y así se estabiliza, deviene estado de dominación, en la apertura unilateral de posibilidades cuya interiorización deviene subjetividad compartida en un modo específico de sujeción. ${ }^{4}$

${ }^{4}$ Respecto de esta noción de dominación, hay un texto donde la distinción indicada entre relaciones de poder y estados de dominación es explícita -más que en otros pasajes, por ejemplo de la historia de la sexualidad, donde Foucault se limita a no negar la existencia de la dominación y decir que se trata sólo de un fenómeno "terminal" (Michel Foucault, 2005: 112ss.). El texto al que nos referimos se trata de una entrevista tardía, de 1984, donde se aprecia con nitidez que, al igual que ocurre con la cuestión del modelo soberano-jurídico de análisis del poder, no es que Foucault niegue su existencia, sino que impugna su "privilegio teórico" en el discurso de la filosofía política tradicional. Hay soberanía, hay estados de dominación. Pero la mirada hay que enfocarla en otra parte: en las relaciones de poder, en la escena material de la historia y la dinámica de sus tensiones concretas -de las cuales, como decíamos, el estado de dominación es sólo la figura terminal. En la entrevista Foucault esboza la distinción diciendo que "las relaciones de poder son relaciones móviles, es decir, pueden modificarse, no están determinadas de una vez por todas. [...] Las relaciones de poder son por tanto móviles, reversibles, inestables. [...] No obstante hay que señalar que existen efectivamente estados de dominación". En los estados de dominación las relaciones de poder "en lugar de ser inestables y permitir a los diferentes participantes una estrategia que las modifique, se encuentran bloqueadas y fijadas. Cuando un individuo o un grupo social consigue bloquear un campo de relaciones de poder haciendo de estas relaciones algo inmóvil y fijo, impidiendo la mínima 
Si consideramos ahora lo que Foucault denomina el arte de vivir, hemos de observar que, como antes señalábamos, la captura de la vida por el dispositivo no es nunca exhaustiva, pues la vida también se escapa, más allá de todo determinismo o reproducción mimética o estratégica de subjetividades instaladas y en vigor. Esto Foucault lo muestra sobre todo al hilo de su tardío trabajo en torno a la historia de la sexualidad, mostrando el límite de nuestra experiencia presente y así desnaturalizándola, mediante el contraste genealógico entre la extrañeza de la experiencia de la "sexualidad" pagana y la familiaridad de la experiencia cristiano-moderna de "la misma", en la que nosotros habitamos -aquí la "mismidad" del fenómeno se revela como un mero supuesto esencialista y, con ello, lo familiar se torna infamiliar. Foucault pone esto a modo de una exposición genealógica del devenir de la cuestión de los usos del cuerpo en su sentido moral y político en Occidente, al hilo de la relación de pliegue entre cuerpo e incorporales -es decir, de prácticas articuladas por la triada saber-poder-moral-, y en esa dirección se retrotrae históricamente a describir cómo se da esto en el mundo griego antiguo en el sentido de una moral estética, moral que se pone en juego como un arte de vivir (téchne, poíesis, bíos) y una limitación del comportamiento por mor del "cuidado de sí" (epiméleia heautou): se trataba entonces, en el contexto de las meditaciones éticas sobre el comportamiento sexual, de inventar una forma de vida libre pero que fuera capaz de conservar su integridad y

reversibilidad de movimientos -mediante instrumentos que pueden ser tanto económicos como políticos o militares-, nos encontramos ante lo que podemos denominar un estado de dominación" (Foucault, 1984: 105). 
autodominio. A eso se dedicaron las preocupadas búsquedas de una miríada de hombres y escuelas en el mundo griego precristiano.

Foucault prosigue esta deriva genealógica considerando el tránsito desde tal moral creativa hacia una moral pastoral durante el ascenso del cristianismo medieval, poniendo de relieve una reconfiguración moral en la que el gobierno de sí de la persona llega a pasar por el desapego a la "vida terrenal" y el autodominio frente a la potencia tentadora de "la carne": obedecer y portarse bien, según un código de comportamiento acuñado bajo el sello de la universalidad y establecido como base del orden jerárquico y clasificatorio de las partes orgánicas del "cuerpo social" como tal. Se trata de una obediencia administrada mediante una serie de tecnologías pastorales que se practican en el seno de la institucionalidad eclesiástica y se ordenan a la promesa de salvación del alma post mortem, de acuerdo a la sujeción del viviente en la tierra al orden de la creación que opera como régimen ontoteológico de deuda. Finalmente, Foucault aborda una modernidad arraigada en la moral cristiana, pero que recodifica el control de la sexualidad en la clave biopolítica de la gubernamentalidad -en virtud de discursos de razón tecnocientífica autorizados y una multiplicidad de instituciones disciplinarias de matriz estatal, las cuales administran la salud y encauzan la utilidad de unos vivientes devenidos sujetos autoconcientes en el plano de la inmanencia mundana y su gramática económico-política, en el contexto general de la gestión de la "cuestión social" en cuanto aseguramiento 
calculado de un régimen de producción de mercancías y de sujetos útiles a la sociedad.

En suma, la operación teórica de Foucault extrema así los indicios del contraste entre la conducción pastoral y la administración biopolítica de la vida por un lado, versus el arte de vivir como práctica de desprendimiento de uno mismo (desobediencia) e invención de sí mismo (disidencia). Sin embargo, su temprano encuentro con la muerte truncó sus investigaciones arqueológico-genealógicas en torno a la deriva occidental de las tecnologías de sujeción, las cuales alcanzaron a desplegarse con mayor detalle sobre la producción de subjetividad que va desde el poder pastoral de corte eclesiástico hasta el poder gubernamental de corte estatal, y sentaron las bases para explorar las tecnologías correspondientes al poder mercantil-veridictivo de corte postestatal, esto es, en el escenario global de una política progresivamente subsumida en una economía desterritorializada -respecto del nomos propiamente estatal, en el sentido moderno clásico (Michel Foucault, 2007: 43ss). En esta última dirección resulta interesante complementar los estudios de Foucault con planteamientos tales como los de Pier Paolo Pasolini sobre el "nuevo fascismo de la civilización del consumo" (1997), los de Gilles Deleuze sobre la "sociedad de control" (1991) y los de Guy Debord sobre la "sociedad del espectáculo" (1995). 
Sobre esta base es posible ganar una perspectiva de la deriva totalitaria moderna, que en la elaboración conceptual de Foucault tiene el carácter de una biopolítica, esto es, de una convergencia y anudamiento del "doble vínculo" entre procedimientos de totalización política y técnicas de individualización moral. Este fenómeno ha sido estudiado también por Giorgio Agamben, en términos de una confluencia entre las dos lógicas del poder occidental de las que Agamben ha hecho la genealogía teológica: la soberanía política y la gubernamentalidad económica. El "estado de excepción" sobre el homo sacer es el núcleo soberano-político -arcano de la máquina gubernamental moderna-, y la producción de subjetividad obediente y "glorificante del reino" es su núcleo gubernamental-económico (Agamben, 1998; 2008). Tanto en Foucault como en Agamben la dominación, en cuanto captura de la potencia del viviente, es concebida como una puesta en obra política y económica en virtud de la violencia: ya mediante tecnologías mortíferas, ya mediante tecnologías productoras de subjetividad. A partir de una puesta en relación de los planteamientos de Arendt y de Foucault, Agamben postula un parentesco entre la biopolítica y el totalitarismo, pues considera que hay un común denominador arcano entre la democracia liberal y el totalitarismo: ambos ejercen el "poder soberano" sobre la "nuda vida".

Si en la perspectiva nominalista de Foucault el término "historia" no es sino el nombre para indicar formalmente un 
despliegue multiforme de relaciones de poder primarias respecto de las relaciones de significación, la historia es ante todo una historia del poder, es decir: la historia de la diseminación y refinamiento de las técnicas de dominación en Occidente, en la que se van superponiendo estratos de tecnología que van desde la violencia más arcaica hasta los más sofisticados dispositivos. Es precisamente aquí donde hallamos un punto de contacto entre el pensamiento del dispositif en Foucault y el pensamiento de lo Gestell en Heidegger: por su condición estructural, la ratio occidental alberga en su seno una íntima tendencia a la dominación total de lo ente. ${ }^{5}$ Es en ese sentido que Foucault, en tensión crítica con la moderna hipótesis hobbesiana, señala lo siguiente:

La humanidad no progresa gradualmente de combate en combate hasta que llega a la reciprocidad universal, donde el imperio de la ley finalmente reemplaza a la guerra; la humanidad instala cada una de sus violencias en un sistema de reglas y así procede de dominación en dominación (Michel Foucault, 1977: 151).

En orden a una consideración específica de lo que aquí denominamos la deriva totalitaria moderna, observemos que Foucault pone entre paréntesis el eje del poder soberanojurídico y enfoca específicamente el lente de su mirada analítica en el eje del poder productivo de subjetividad. Un momento clave en su perspectiva genealógica es, desde el siglo XVI hasta su eclosión en los siglos XVIII y XIX, en Europa, el gran proceso de metamorfosis que acontece en la

${ }^{5}$ Cfr. Heidegger, "Die Frage nach der Technik", en Vorträge und Aufsätze, Teil I, Günther Neske Verlag, Pfullingen, ${ }^{3} 1967$. Ver también Heidegger, "La época de la imagen del mundo", en Caminos de bosque, traducción del alemán al español por Helena Cortés y Arturo Leyte, Editorial Alianza, Madrid, ${ }^{1} 1996$. 
lógica de este poder, desde su modalización medieval como poder pastoral hacia su modalización secularizada como moderno poder normalizador. Se trata de un tránsito progresivo desde la lógica de la conducción religiosa del "rebaño" hacia la superposición expansiva de una lógica de disposición sobre la vida como organización racional de la "población". La biopolítica funcionó así, desde este período, como "un elemento indispensable en el desarrollo del capitalismo", porque puso en obra "un ajuste de los fenómenos de población a los procesos económicos". La biopolítica fue así la articulación estratégica entre el poder político territorializado de los Estados soberanos y el poder económico desterritorializado del capitalismo mundial -he ahí que "el nacimiento de la biopolítica", según Foucault, coincide con la génesis de la "gubernamentalidad liberal". En cualquier caso, lo que se pone en juego es una modalización de la misma lógica del poder de captura, incorporación y conducción de los hombres, pues si bien este proceso de mutación conlleva un relevo de la institución eclesiástica por una multiplicidad de instituciones de matriz estatal, la función productiva de subjetividad se conserva. Foucault lo pone así:

Aquello que durante siglos se llamó en la iglesia griega téchne technôn y en la iglesia romana latina ars artium, era precisamente la dirección de conciencia; era el arte de gobernar a los hombres. Por supuesto que este arte de gobernar permaneció mucho tiempo ligado a prácticas relativamente limitadas, incluso en la sociedad medieval, ligado a la existencia conventual, ligado a y practicado sobre todo en grupos espirituales relativamente restringidos. Pero creo que, a partir del siglo XV y antes de la Reforma, se puede decir que ha habido una verdadera explosión del arte de gobernar a los hombres; explosión que puede entenderse en dos sentidos. 
Primero, como un alejamiento de su original núcleo religioso; digamos, como laicización, expansión hacia la sociedad civil de este tema del arte de gobernar a los hombres y de los métodos para hacerlo. Segundo, como una diseminación de este arte de gobernar en dominios variados tales como gobernar a los niños, a los pobres y a los mendigos, una familia, una casa, a los ejércitos, a las ciudades, a los Estados, al propio cuerpo, al propio espíritu (Michel Foucault, 1995: 35).

Así, lo que caracteriza a este momento histórico del devenir de la lógica del poder productivo de subjetividad es la potenciación incondicionada de su carácter expansivo y multiplicativo, en rigor totalizante: la gubernamentalización (gouvernamentalisation) diseminada a ras del "cuerpo social", con sus tecnologías de gobierno de los hombres llegando a todos los rincones, a lo largo y ancho de los territorios de los Estados modernos, más allá de los límites restringidos del alcance del dispositivo eclesiástico que articulaba la unidad de la cristiandad medieval.

Es en este punto donde resulta interesante remitirnos al vínculo que ha señalado Rodrigo Karmy entre los conceptos biopolíticos de gubernamentalidad y civilización (2012) -en conexión con la idea de Foucault de "emplazamiento" como normalización y aseguramiento de la espacialidad. Al hilo de una genealogía de la razón civilizatoria moderna, Karmy señala la coincidencia en la eclosión, durante el siglo XVIII, de lo que Foucault llama arte liberal de gobernar o "gubernamentalidad" (gouvernamentalité), y del concepto ilustrado de "civilización" (civilisation), rastreable este último al menos a partir de las obras de Mirabeau y Condorcet. En el siglo XVIII europeo, el común denominador de ambos conceptos es su raíz inmediata en lo que entonces se llamaba 
police, es decir: el esfuerzo sistemático por hacer que los individuos "observen espontáneamente" las normas de la sociedad. Producción de subjetividad como interiorización de la obediencia. A partir de la medida dada por la lógica soberana de la partición amigo/enemigo, la lógica gubernamental inscribe a los hombres en la gramática económica de la ciudad moderna a través de una serie de tecnologías que constituyen la "sociedad disciplinaria", mediante la docilización de los cuerpos y la ortopedia moral. La lógica civilizacional, por su parte, pone en juego la misma lógica soberana de la partición amigo/enemigo, pero traducida a la partición civilizado/bárbaro en virtud de la cual se autoafirma la "civilización occidental", con todos sus rendimientos en términos de discriminación (barbarización de los inmigrantes) y colonialismo (barbarización de los pueblos no occidentales). En virtud del imaginario humanista que establece la cesura entre hombre y animal, el imaginario jerárquico-clasificatorio del "bárbaro" implica la proyección de un "otro" inferior y educable, explotable, o en último término simplemente sacrificable.

Karmy observa que el surgimiento de la sociedad disciplinaria advertido por Foucault coincide con la puesta en juego de la agencia civilizacional -de un Occidente cuya articulación metafísico-imaginal es onto-teo-antropológica, agregaríamos nosotros. De tal modo que la deriva totalitaria moderna, a modo de imperialismo occidental, se expresa en la multiplicación intensiva de sus tecnologías (como "urbanización" metropolitana de las formas de vida), pero también como un dispositivo invasivo en expansiva (una 
economía desterritorializada, una forma de vida que se intenta imprimir a otros vivientes) al hilo del mito de su propia "filosofía de la historia" (una historia de la humanidad interpretada como historia del "conflicto entre civilización y barbarie", es decir, entre el perfeccionamiento humano y la resistencia a tal teleología).

\section{III}

Más allá de todo determinismo o reproducción mimética de subjetividades instaladas, la captura de la vida por los dispositivos no es nunca exhaustiva, pues la vida también se escapa en el interior del dominio del mismo dispositivo ya territorializado o le es extraña más allá de sus fronteras territoriales vigentes. Aquí es donde aparece, a la luz de las actuales configuraciones geopolíticas del poder económicopolítico, la exigencia de una distinción entre la gubernamentalidad metropolitana y la gubernamentalidad neocolonial, y con ello la urgencia por romper los cercos disciplinarios que se han institucionalizado en el seno del dispositivo universitario entre las perspectivas biopolíticas, por una parte, y los estudios coloniales y post-coloniales por otra.

En cualquier caso, lo que queda por seguir pensando es la tensión infinita entre la totalización moderna de los dispositivos gubernamentales y la proliferación de la vida pagana. El término latino pāgānismus fue acuñado durante el medioevo a partir de la palabra pāgus, que nombra lo que nosotros llamamos el campo, en el sentido de lo rural, el 
espacio no urbanizado en que no obstante se despliega la vida. El término pāgus se usaba para referir a aquellos lugares a los que no llegaban -aún- las instituciones productoras y vigilantes de la subjetividad cristiana. Más allá de la vida conventual o de las comunidades que se agrupaban en torno a las capillas de las ciudades y pueblos, más allá de ello se abría el ámbito del paganismo, el afuera de los paganos: vida no convertida, vida salvaje. Algunos sentidos a los que podríamos aproximar la expresión "el afuera de los paganos", para indicar hacia la proliferación pagana de la vida en medio de los dispositivos contemporáneos, podrían ser, por ejemplo, aquellos como el de la noción de un "arte de vivir" en Foucault, con su carga de ingobernabilidad reflexiva y disidencia creativa, o el sentido de la idea de "línea de fuga" que aparece en Deleuze y Guattari (2002).

Quizás una experiencia radicalmente pagana no pueda sino constituirse como revocación de la gloria del reino: la experiencia del "afuera" como la potencia de una cierta vida ateológica y anárquica que ponga en cuestión la ontoteología de la metafísica que articula el proyecto civilizatorio occidental. Una vida ateológica y anárquica que como tal reivindique la potencia de otra relación entre vida y forma, una relación que implique una circulación sin acumulación soberano-equivalencial de la vida y sus producciones -contra las formas occidentales hegemónicas de circulación con patrón de acumulación en las esferas política, económica, estética, semántica, o en último término, moral (forma de vida civilizada). Contra la acumulación de poder en la esfera político-representacional, radicalización de la democracia. 
Contra la acumulación económico-capitalista, contención de las fuerzas de apropiación privada. Contra la acumulación espectacular de la estética policial, la potencia común de la imaginación. Contra la acumulación semántica de los discursos hegemónicos y autorizados, la puesta en cuestión de los significados y la profanación de los significantes. Contra el patrón de acumulación moral de formas de vita bona que operan como normas antropológicas civilizatorias, la proliferación pagana de las formas de vida.

\section{IV}

El filósofo francés Georges Didi-Huberman, en su libro Supervivencia de las luciérnagas (2009), ensaya una interesante aproximación a las cuestiones aquí tratadas, en conexión con una lectura de los planteamientos de Pier Paolo Pasolini sobre el "nuevo fascismo". En febrero de 1975, el poeta-cineasta publicó en la prensa italiana una carta, conocida como el artículo sobre "la desaparición de las luciérnagas" (la disparition des lucioles), en que se lamentaba con tal imagen de la desaparición en Italia de los hombres que se resistían a ser domesticados por la civilización del consumo. La imagen, según explica Didi-Huberman (2012: 7ss), está tomada de Dante de Alighieri (Divina comedia, Infierno, XXVI): arriba está el Paraíso, el cielo con su gran "luz" (lume, luce), luz celestial que define el cosmos con su gloria escatológica; abajo está el Infierno con sus pequeñas y errantes "lucecitas" (lucciole), constelación de pequeñas 
llamas que son las almas errantes, luciferinas, expulsadas del cosmos, ardiendo en su propio fulgor doloroso, en un castigo sin fin, pues "cada llama envuelve a un pecador" (ogni fiamma un peccatore invola). En el octavo círculo del infierno Dante sitúa el lugar donde vagan como luciérnagas los "consejeros pérfidos" condenados como tales -por ejemplo, los acaudalados nobles de Florencia que fundían el arte de gobernar con los negocios: el negocio de la política, la política del dinero. Didi-Huberman muestra que Pasolini alude a esta imagen de Dante, pero en alegoría de una actualidad que expone una inversión completa de las relaciones entre luce y lucciole: en nuestros días son los "consejeros pérfidos" políticos y empresarios- los que están en el cielo, en la gloria del reino, en la sobreexposición de la gran luz mediática y televisual, mientras que los hombres del pueblo sin ese poder económico-político, errantes en la oscuridad como luciérnagas, buscan como pueden su libertad de movimiento: huyendo de los proyectores del reinado hacia la noche, emitiendo y compartiendo entre ellos sus propios resplandores. En este cuadro los políticos y empresarios se agitan triunfales en un infierno económico muy bien iluminado -en un espejismo que forma sistema con la gloria del reino-, mientras las luciérnagas del pueblo, expulsadas de ese cosmos espectacular, persisten en su resistencia activa (los rebeldes) o pasiva (los excluidos). Se trata, pues, de un universo dantesco de algún modo invertido.

Las luciérnagas (lucioles), en el léxico de Pasolini, nombran la vida como instancia e intersticio de transgresión revolucionaria: nostalgia de la inocente infancia (dell'innocente 
infanzia), hombres y mujeres que "parecen haber vuelto a ser niños inocentes" (come quando sembrano ridiventati fanciulli innocenti). Didi-Huberman:

Lo esencial sigue siendo esa alegría inocente y poderosa que aparece como una alternativa a los tiempos demasiado oscuros o demasiado iluminados del fascismo triunfante. / [...] El arte y la poesía valen también por semejantes resplandores a la vez eróticos, alegres e inventivos. / [...] La carta de Pasolini finaliza y culmina con el contraste violento entre esta excepción de la alegría inocente, que recibe o irradia la luz del deseo, y la regla de una realidad hecha culpabilidad, mundo de terror [...]. Toda la obra literaria, cinematográfica e incluso política de Pasolini parece atravesada por semejantes momentos de excepción en los que los seres humanos se vuelven luciérnagas -seres luminiscentes, danzantes, erráticos, inaprensibles y, como tales, resistentes [...]. / La danza de las luciérnagas, ese momento de gracia que resiste al mundo del terror, es la cosa más frágil y fugaz (2012: 14-18).

Pero en la carta de 1975 Pasolini habla de la disparition des lucioles. Como dice Didi-Huberman, "la luciérnaga está muerta, ha perdido sus gestos y su luz en la historia política de nuestra oscura contemporaneidad que condena a muerte a su inocente". Pasolini refiere con esto a una catástrofe que coincide con el tránsito de la sociedad disciplinaria a la sociedad de control: se trata de un proceso de "aculturación" (acculturazione) que no es sino el anverso fenoménico de la recepción sin crítica del "modelo" neoliberal por parte de los padres y los hijos italianos. Este proceso se ha cumplido "sin verdugos ni ejecuciones masivas", y ha consistido más bien en la "asimilación al modo y la cualidad de vida de la burguesía". Pero el tono de las últimas declaraciones de Pasolini en los años setenta es confrontado por DidiHuberman, cuya tesis interpretativa sobre el tópico de la 
desaparición de las luciérnagas destaca la persistencia de una negatividad inmanente, intersticial, que habla de la "supervivencia de las luciérnagas". Didi-Huberman:

\begin{abstract}
¿Ve entonces Pasolini su entorno contemporáneo como una noche que habría definitivamente devorado, sometido o reducido las diferencias que forman, en la oscuridad, las sacudidas luminosas de las luciérnagas en busca de amor? Creo que esta última imagen no es la buena todavía. En efecto, no es en la noche donde las luciérnagas han desaparecido. En lo más profundo de la noche, somos capaces de captar el menor resplandor, y es la expiración misma de la luz la que nos resulta todavía visible en su estela, por tenue que sea. No, las luciérnagas han desaparecido en la cegadora claridad de los "feroces reflectores": reflectores de los miradores y torres de observación, de los shows políticos, de los estadios de fútbol, de los platós de televisión. [...] / ¿Está el mundo tan totalmente sometido como han soñado -como proyectan, programan y quieren imponernos- nuestros actuales "consejeros pérfidos"? Postularlo así es, justamente, dar crédito a lo que su máquina quiere hacernos creer. Es no ver más que la noche negra o la luz cegadora de los reflectores. Es actuar como vencidos: es estar convencidos de que la máquina hace su trabajo sin descanso ni resistencia. Es no ver más que el todo. Y es, por tanto, no ver el espacio -aunque sea intersticial, intermitente, nómada, improbablemente situado- de las aberturas, de las posibilidades, de los resplandores, de los pese a todo (2012: 22, 31).
\end{abstract}

\title{
Bibliografía
}

Agamben, Giorgio. (1998). Homo sacer I. El poder soberano y la nuda vida. Traducción del italiano al español por Antonio Gimeno. Valencia: Editorial Pre-Textos.

Agamben, Giorgio. (2008). Homo sacer II, 2. El reino y la gloria. Para una genealogía teológica de la economía y del 
gobierno. Traducción del italiano al español por Antonio Gimeno Valencia: Editorial Pre-Textos.

BUTLER, Judith. (2001). Mecanismos psíquicos del poder. Teorías sobre la sujeción. Traducción del inglés al español por Jacqueline Cruz. Madrid: Ediciones Cátedra.

Debord, Guy. (1995). La sociedad del espectáculo. Traducción del francés al español por Rodrigo Vicuña. Santiago: Editorial Naufragio.

Deleuze, Gilles. (1991). "Posdata sobre las sociedades de control". En: Ferrer, Christian (comp.). El lenguaje literario, Tomo 2. Montevideo: Editorial Nordan.

Deleuze, Gilles y Guattari, Félix. (2002). Mil mesetas. Capitalismo y esquizofrenia. Traducción del francés al español por José Vásquez. Valencia: Editorial Pre-Textos.

DidI-HubeRmAN, Georges. (2012). Supervivencia de las luciérnagas. Traducción del francés al español por Juan Calatrava. Madrid: Abada Editores.

Foucault, Michel. (1992). "Nietzsche, la genealogía y la historia". En: Foucault, Michel. Microfísica del poder. Traducción del francés al español por Julia Varela y Fernando Álvarez-Uría. Madrid: Editorial La Piqueta. 
FoucAULt, Michel. (1995). "Crítica y Aufklärung". Revista de Filosofía ULA, 8, 33-45.

FOUCAULT, Michel. (2004). Vigilar y castigar. Traducción del francés al español por Aurelio Garzón. Buenos Aires: Ediciones Siglo XXI.

FOUCAULT, Michel. (2005). Historia de la sexualidad, Volumen 1. Traducción del francés al español por Ulises Guiñazú. Buenos Aires: Ediciones Siglo XXI.

FOUCAULT, Michel. (1984) "La ética del cuidado de uno mismo como práctica de la libertad" (Entrevista con Foucault realizada por Raúl Fornet-Betancourt, Helmut Becker y Alfredo Gómez-Muller). Revista Concordia, 6, 96-116.

Foucault, Michel. (2007). Nacimiento de la biopolítica. Traducción del francés al español por Horacio Pons: México: Editorial F.C.E.

Foucault, Michel. (2000). Defender la sociedad (Curso en el Collège de France, 1975-1976). Traducción del francés al español por Horacio Pons: México: Editorial F.C.E.

FOUCAULT, Michel. (1977). Language, counter-memory, practice. Selected essays and interviews. Traducción del francés al inglés por Donald Bouchard. New York: Cornell University Press. 
HEIDEGGER, Martin. (1967). "Die Frage nach der Technik". En: Vorträge und Aufsätze, Teil I. Pfullingen: Günther Neske Verlag.

HeidegGer, Martin. (1996). "La época de la imagen del mundo". En: Caminos de bosque. Traducción del alemán al español por Helena Cortés y Arturo Leyte. Madrid: Editorial Alianza.

KARMY, Rodrigo. (2012) "La potencia de la Intifada. Prolegómenos para una genealogía de la razón civilizatoria". Revista Archivos, 6-7, 147-188.

PAsolinI, Pier Paolo. (1997). Cartas Luteranas. Traducción del italiano al español por Josep Torrell y otros. Madrid: Editorial Trotta. 